\title{
Random regression test-day model for clinical mastitis: Genetic parameters, model comparison, and correlations with indicator traits
}

\author{
E. Gernand* and S. Königt ${ }^{1}$ \\ *Thuringian State Institute of Agriculture, 07743 Jena, Germany \\ †Department of Animal Breeding, University of Kassel, 37213 Witzenhausen, Germany
}

\begin{abstract}
The objective was to study genetic (co)variance components for binary clinical mastitis (CM), test-day protein yield, and udder health indicator traits [test-day somatic cell score (SCS) and type traits of the udder composite] in the course of lactation with random regression models (RRM). The study used a data set from selected 15 large-scale contract herds including 26,651 Holstein cows. Test-day production and CM data were recorded from 2007 to 2012 and comprised parities 1 to 3. A longitudinal CM data structure was generated by assigning CM records to adjacent official test dates. Bivariate threshold-linear RRM were applied to estimate genetic (co)variance components between longitudinal binary CM ( 0 = healthy; $1=$ diseased $)$ and longitudinal Gaussian distributed protein yield and SCS testday data. Heritabilities for liability to CM (heritability $\sim 0.15$ from 0 to $305 \mathrm{~d}$ after calving) were slightly higher than for SCS for corresponding days in milk (DIM) in the course of lactation. Daily genetic correlations between CM and SCS were moderate to high (genetic correlation $\sim 0.70$ ), but substantially decreased at the very end of lactation. Genetic correlations between CM at different test days were close to 1 for adjacent test days, but were close to zero for test days far apart. Daily genetic correlations between $\mathrm{CM}$ and protein yield were low to moderate. For identical DIM (e.g., DIM 20, 160, and 300), genetic correlations were -0.03 , 0.11 , and 0.18 , respectively, and disproved pronounced genetic antagonisms between udder health and productivity. Correlations between estimated breeding values (EBV) for CM from the RRM and official EBV for linear type traits of the udder composite, including EBV from 74 influential sires (sires with $>60$ daughters), were -0.31 for front teat placement, -0.01 for rear teat placement, -0.31 for fore udder attachment, -0.32 for udder depth, and -0.08 for teat length. Estimated
\end{abstract}

Received December 13, 2013.

Accepted February 24, 2014.

${ }^{1}$ Corresponding author: sven.koenig@uni-kassel.de breeding values for $\mathrm{CM}$ from the RRM were compared with EBV from a multiple-trait model and with EBV from a repeatability model. For test days covering an identical time span and on a lactation level, correlations between EBV from RRM, multiple-trait model, and repeatability model were close to 1 . Most relevant results suggest the routine application of threshold RRM to binary CM to (1) allow selection of genetically superior sires for distinct stages of lactation and (2) achieve higher selection response in CM compared with selection strategies based on indicator type traits or based on the indicator-trait SCS.

Key words: clinical mastitis, random regression model, indicator trait

\section{INTRODUCTION}

Test-day models have been the standard methodological tool used in official genetic evaluations for Gaussian distributed longitudinal production traits and SCS for almost 2 decades. The first relevant scientific studies for the estimation of genetic parameters in the course of lactation were accomplished by Meyer et al. (1989) and by Ptak and Schaeffer (1993) for milk yield, and by Reents et al. (1995) for SCS. Strategies for analyzing longitudinal test-day data were summarized and compared by Swalve (2000). Strategies included the comparison of repeatability models with multiple-trait models, and the comparisons of test-day models using fixed regressions, covariance functions, and random regressions. Random regression models (RRM) present the genetic trajectory of the longitudinal trait in the course of a time-dependent or an environmental continuous descriptor, or both (e.g., Brügemann et al., 2011). Breeding values for each test day allow the use of different selection criteria (e.g., the selection of animals characterized by desired measurements for lactation persistency; Jamrozik et al., 1997). In most RRM applications to longitudinal data, regressions were modeled based on Legendre polynomials. Baldi et al. (2010) used RRM with Legendre polynomials to fit all random components, including direct genetic, maternal genetic, 
animal permanent environmental, and maternal permanent environmental effects.

Random regression models also were applied to longitudinal binary data structures by including threshold methodology. Random regression threshold sire models were fitted for the genetic analyses of binary conception rate by DIM (Tsuruta et al., 2009), and by temperature $\times$ humidity indices (Brügemann et al., 2013). A recent focus on the implementation of health data-recording systems enables substantial data sets for health traits as a prerequisite for RRM applications also to binary health data. Among health traits, priority is on genetic improvements for clinical mastitis (CM). This is due to the obvious effect of $\mathrm{CM}$ on involuntary dairy cow disposals, and due to the detrimental effect of CM on dairy farming profitability and economy (e.g., SadeghiSefidmazgi et al., 2011).

The direct inclusion of $\mathrm{CM}$ into an overall breeding goal, the improvement of breeding goals, and the definition of breeding strategies requires knowledge of genetic correlations with production traits, and with currently used indicator traits for udder health. The most important indicator trait for CM is SCS, and estimates for genetic correlations $\left(\mathbf{r}_{\mathrm{g}}\right)$ between $\mathrm{CM}$ and SCS from lactation models were $r_{\mathrm{g}} \approx 0.70$ (e.g., Emanuelson et al., 1988). Indicator traits for CM additionally include linear type traits of the category "udder." Among linear type traits, best predictors were udder depth, udder attachment, and udder balance (Rupp and Boichard, 1999). The direct inclusion of health traits into an overall breeding goal raises the question about the necessity of indicator trait recording. König et al. (2013) applied selection index methodology to phenotypic and genomic information sources. In their study, selection response in the targeted health trait decreased with a stepwise increase of health indicator traits in the breeding goal. In the study by de Haas et al. (2002), an indirect selection strategy based on milk yield and SCS was ineffective in reducing simultaneously incidences of the whole spectrum of specific major pathogens for CM.

Following those aspects for reducing $\mathrm{CM}$ incidence by genetic selection, the objective of the present study was 4-fold: to (1) to estimate genetic (co)variance components of $\mathrm{CM}$ in the course of lactation, (2) estimate genetic correlations between CM and milk yield in the course of lactation, (3) estimate correlations between breeding values for $\mathrm{CM}$ and breeding values for indicator type traits in the course of lactation, and (4) compare EBV for CM from the threshold RRM with EBV for CM from more robust repeatability models (RM) and multiple-trait models (MTM).

\section{MATERIALS AND METHODS}

\section{Data}

Holstein cows used in this study were the same as used in the study by Gernand et al. (2013) for the genetic analysis of claw disorders in the course of lactation. Also for CM, data recording in a "contract herd system," including 15 large-scale herds in the state of Thuringia, was based on the diagnosis key by Feucker and Staufenbiel (2003). This diagnosis key is implemented in electronically on-farm recording systems. The contract herd system implies a strong collaboration between the breeding organization and dairy cattle farms, and advantages of such a system in terms of health data quality and quantity was outlined in several previous studies (e.g., Gernand et al., 2012, 2013). Data recording spanned a period of 5 yr from 2007 to 2012, and included 26,651 Holstein cows from parities 1 to 3. Longitudinal CM data were generated as described in detail by Gernand et al. (2013) and illustrated in Figure 1. The first and major feature of this strategy is to create time windows between consecutive official test days. Official test days are in monthly intervals and, consequently, the length of time intervals is approximately $30 \mathrm{~d}$. In the second step, we assigned CM cases to exactly the date of the adjacent official test day. Hence, diseased cows (1 or more CM cases within a given interval) received a score of 1 and healthy cows received a score of 0 at the official test date. Based on this methodology, a substantial data set of repeated binary measurements was created (Table 1 ). The number of test days per herd ranged from 11,967 to 63,194 . Furthermore, for the application of MTM, we divided the lactation into 4 periods (Figure 1): period I comprised DIM 1 to 60, period II DIM 61 to 180, period III DIM 181 to 270 , and period IV DIM 271 to 360.

The genetic structure of the contract herd cows was characterized as follows: the 26,651 cows were from 1,258 different sires, which implies, on average, 21 daughters per sire and 74 sires with more than 60 daughters for all traits. National official EBV from these 74 sires were available from the genetic evaluation of August 2012. In the present study, we used official EBV for the overall index, the conformation index, the longevity index, the SCS index (RZS), the production index, the milking speed index (RZD), and the udder type trait index as well as relative breeding values for linear type traits of the udder composite, including rear udder height, central ligament, front teat placement (FTP), rear teat position (RTP), fore udder attachment, udder depth, and teat length (TL). Relative official national breeding values are standardized to a mean of 100 and a 
Table 1. Distribution of herd-test-day-milking-frequency classes and number of observations per class

\begin{tabular}{lcc}
\hline $\begin{array}{l}\text { No. of cows per } \\
\text { herd-test-day-milking-frequency class }\end{array}$ & $\begin{array}{c}\text { No. of } \\
\text { classes }\end{array}$ & $\begin{array}{c}\text { No. of } \\
\text { observations }\end{array}$ \\
\hline$<200$ & 65 & 9,210 \\
$201-500$ & 254 & 78,291 \\
$501-1,000$ & 277 & 190,954 \\
$>1,000$ & 111 & 127,872 \\
\hline
\end{tabular}

standard deviation of 12 points. Estimated breeding values for CM had a mean of 0 and a standard deviation of 1 point. Hence, EBV $<0$ for CM were favorable in the sense of breeding, and indicated lower disease incidences of daughters.

\section{Statistical Models}

$\boldsymbol{R} \boldsymbol{R} \boldsymbol{M}$. The major focus of this study was the application of RRM to binary longitudinal CM. Hence, univariate threshold RRM only including $\mathrm{CM}$, and bivariate threshold-linear RRM including 1 binary $(\mathrm{CM})$ and 1 Gaussian trait (test-day protein yield and test-day SCS in consecutive runs) were applied. The threshold RRM was identical compared with the study by Gernand et al. (2013) as used for binary claw disorders. In matrix notation, the threshold linear RRM was as follows:

$$
\left[\begin{array}{l}
\mathbf{l} \\
\mathbf{y}
\end{array}\right]=\left[\begin{array}{l}
\mathbf{X} \boldsymbol{\beta}+\mathbf{Z u}+\mathbf{W p e}+\mathbf{e} \\
\mathbf{X} \boldsymbol{\beta}+\mathbf{Z u}+\mathbf{W p e}+\mathbf{e}
\end{array}\right]
$$

where $\mathbf{l}=$ vector of unobserved liabilities for $\mathrm{CM}$, with the binary outcome $1=$ diseased or $0=$ healthy; $\mathbf{y}=$ vector of observations for test-day protein yield or testday SCS; $\boldsymbol{\beta}=$ vector of fixed effects, including herdtest-date-milking-frequency classes, age at calving, and regressions on DIM within parities using Legendre polynomials of order $3 ; \mathbf{u}=$ vector of random additive genetic effects, with regressions on DMI using Legendre polynomials of order 3 ; pe $=$ vector of random permanent environmental effects for cows, with regressions on DMI using Legendre polynomials of order $3 ; \mathbf{X}, \mathbf{Z}$, and $\mathbf{W}$ are the associated incidence matrices; and $\mathbf{e}=$ vector of random residual effects. Legendre polynomials were standardized between 1 and $365 \mathrm{~d}$ after calving. In consecutive univariate runs, heritabilities and EBV for CM were compared using an RMM with Legendre polynomials of order 4 for fixed and random effects (if not explicitly mentioned in the text, results are based on Legendre polynomials of order 3 ).

As shown by Gernand et al. (2013), such a modeling implies the following (co)variance structure:

$$
\operatorname{var}\left[\begin{array}{l}
\boldsymbol{\beta} \\
\boldsymbol{\delta} \\
\mathbf{e}
\end{array}\right]=\left[\begin{array}{ccc}
\mathbf{K}_{\beta} \otimes \mathbf{A} & 0 & 0 \\
0 & \mathbf{K}_{\delta} \otimes \mathbf{I}_{\mathrm{j}} & \\
& & \mathbf{K}_{\mathrm{r}}
\end{array}\right],
$$

where $\mathbf{K}_{\beta}=$ (co)variance matrix of random regression coefficients for direct genetic effects by DIM; $\mathbf{A}=$ additive genetic relationship matrix (depth of the pedigree was 4 generations); $\mathbf{K}_{\delta}=$ (co)variance matrix of random regression coefficients for permanent environmental effects by DIM; $\mathbf{I}_{\mathrm{j}}=$ an identity matrix, with $\mathrm{j}$ denoting the number of cows with records; and $\otimes=$ Kronecker product. For residual variances, a diagonal matrix $\left(\mathbf{K}_{\mathrm{r}}\right)$

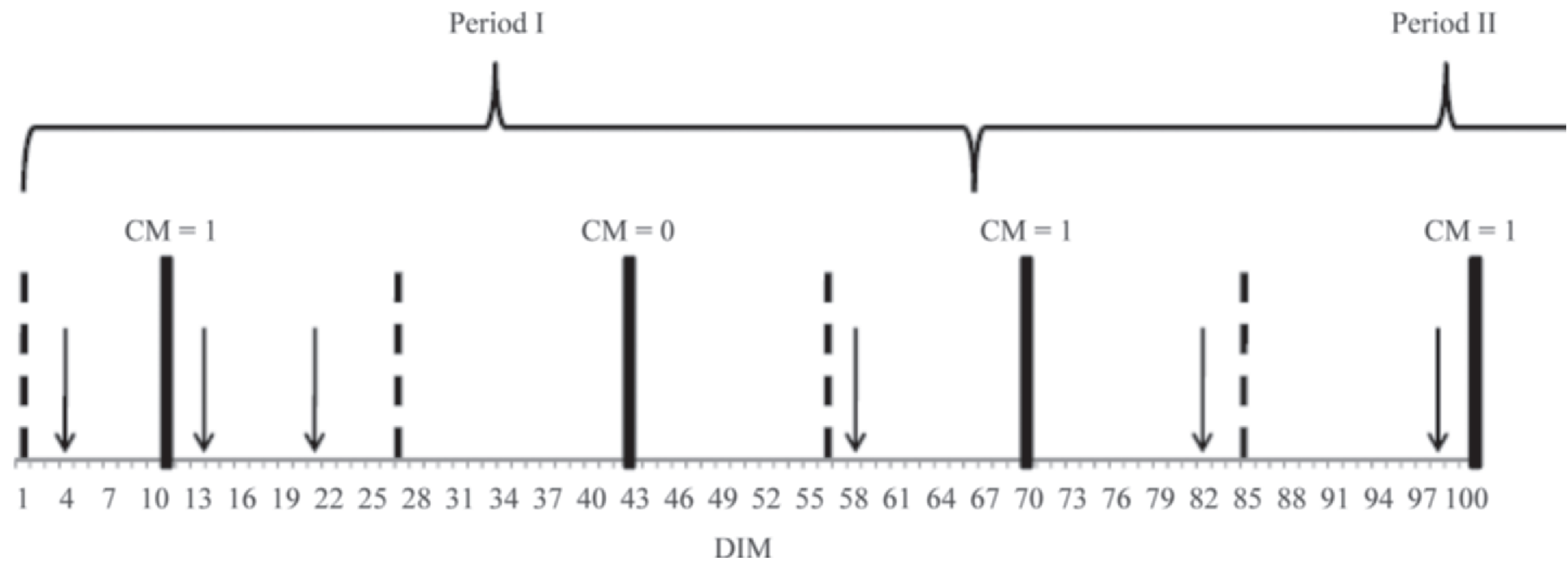

Figure 1. Example of data preparation for 1 cow for analyses of clinical mastitis [CM; adopted from Gernand et al. (2012), but modified with regard to data preparation for the multiple-trait model]. Arrows = occurrence of CM; black bars = date of official test days for production traits; dashed lines = thresholds of defined time windows for assigning occurrences of CM to the nearest official test date; period I $=$ test days from d 1 to 65; period II = test days from d 66 to 180. This example illustrates the beginning of lactation, but subsequently, period III (test days from d 181 to 270 ) and period IV (test days from d 271 to 360 ) were created. 
was modeled. Lactation EBV of sires for CM were the sum of daily EBV and calculated following the method of Jamrozik et al. (1997). The residual variance for binary traits was fixed to 1 and the residual standard deviation for Gaussian traits protein yield and SCS was constant in the course of lactation (153.61 g and 1.30, respectively).

$\boldsymbol{R} \boldsymbol{M}$. Additionally and following Gernand et al. (2012), the longitudinal test-day binary data were analyzed by applying threshold RM. Basically, the statistical model in matrix notation was the same as the RRM by simplifying the random additive genetic and permanent environmental effects. Hence, $\mathbf{u}=$ vector of random additive genetic effects and $\mathbf{p}=$ vector of random permanent environmental effects for cows, without modeling random regression coefficients. The (co)variance structure for random effects for the RM was as follows:

$$
\operatorname{var}\left[\begin{array}{l}
\mathbf{u} \\
\mathbf{p} \\
\mathbf{e}
\end{array}\right]=\left(\begin{array}{ccc}
\sigma_{\mathrm{g}}^{2} \mathbf{A} & \mathbf{0} & \mathbf{0} \\
\mathbf{0} & \sigma_{\mathrm{p}}^{2} \mathbf{I} & \mathbf{0} \\
\mathbf{0} & \mathbf{0} & \sigma_{\mathrm{e}}^{2} \mathbf{I}
\end{array}\right),
$$

where $\sigma_{\mathrm{g}}^{2}, \sigma_{\mathrm{p}}^{2}$, and $\sigma_{\mathrm{e}}^{2}$ denote variances of additive genetic, permanent environmental, and residual effects, respectively, and $\mathbf{I}$ is an identity matrix.

MTM. Clinical mastitis recorded in the 4 different periods were denoted as 4 different traits. For such a data structure, a fourth-trait threshold MTM was applied. The MTM was identical to the RM by excluding the permanent environmental effect.

Solving of mixed-model equations was done using Bayesian procedures and Gibbs sampling, as implemented in the software package DMU (Madsen and Jensen, 2000). Based on the visual inspections of changes of genetic covariances in consecutive iterations, and based on previous experience with Bayes procedures for the genetic analyses on binary health data (Gernand et al., 2013), chain lengths of 300,000 samples were determined. The first 50,000 samples were discarded as so called burn-in rounds, and results from 250,000 samples were used to infer genetic (co)variance components.

\section{RESULTS AND DISCUSSION}

\section{Incidences of CM in the Course of Lactation}

The lactation curve (Figure 2) showing CM incidences at individual test days revealed a maximum of mastitis incidences at the beginning of lactation and a minimum of incidence rates at the end. This was found in several previous studies [e.g., a maximum of mastitis incidences within the first $30 \mathrm{~d}$ after calving in a recent study by Zoche-Golob and Spilke (2013)]. Those authors created similar time intervals as done in our study for detailed within-herd analyses and for studying associations between CM and milk yield. Higher CM incidences at the beginning of lactation are presumably due to the phenomenon of metabolic stress as assessed by levels of some metabolic parameters and blood leukocyte profiles (Holtenius et al., 2004). Rehbein et al. (2013) found that high milk yield, especially directly after calving, increased susceptibility to CM. In the ongoing lactation, high CM incidences increased the risk of involuntary dairy cow disposals (Hertl et al., 2011). Also, in the present study, CM occurred more frequently early in lactation in periods I and II, with a mean incidence of 0.17 and 0.18 , respectively, than in periods III and IV, with mean incidences of 0.11 . Test-day SCS was highest directly after calving, had a minimal value in the peak phase of lactation, and increased from the middle to the end of lactation (Figure 2 ). Hence, patterns for CM and SCS differed in the last third of lactation. Gernand et al. (2012) found a weak relationship between SCS and CM in the late stage of lactation. Cows with high values for SCS did not show the obvious signs of CM (i.e., an udder infection with rubor, dolor, and changes of color).

\section{Genetic Parameters of $\mathrm{CM}$ in the Course of Lactation}

Heritabilities for liability to $\mathrm{CM}$ in the course of lactation from the univariate threshold model were congruent with heritabilities from the bivariate threshold-linear model including binary $\mathrm{CM}$ and Gaussian-distributed protein yield, and from the bivariate threshold-linear model including binary $\mathrm{CM}$ and Gaussian-distributed SCS (Figure 3). Heritabilities were quite constant at approximately 0.15 in the interval from calving to 305 DIM. Afterward, heritabilities increased with increasing DIM, and a maximal value of 0.33 was estimated at the end of the defined continuous time scale (d 365). Highest heritabilities and additive genetic variances extremely late in lactation were also observed for categories of claw disorders by Gernand et al. (2013). In their study, results were explained by artifacts of the RRM (i.e., sensitivity of sophisticated and overparameterized statistical models to small data sets and extremely low disease incidences beyond DIM 305). Carlén et al. (2009) also chose third-order Legendre polynomials for RRM applications to CM, but they standardized polynomials within a narrow time interval from $10 \mathrm{~d}$ before to $241 \mathrm{~d}$ after calving. In their study, heritabilities for $\mathrm{CM}$ were quite low, and the highest value was estimated before calving $\left(\mathrm{h}^{2} \approx 0.02\right.$ from $\mathrm{a}$ linear model). Moderate heritabilities for liability to 


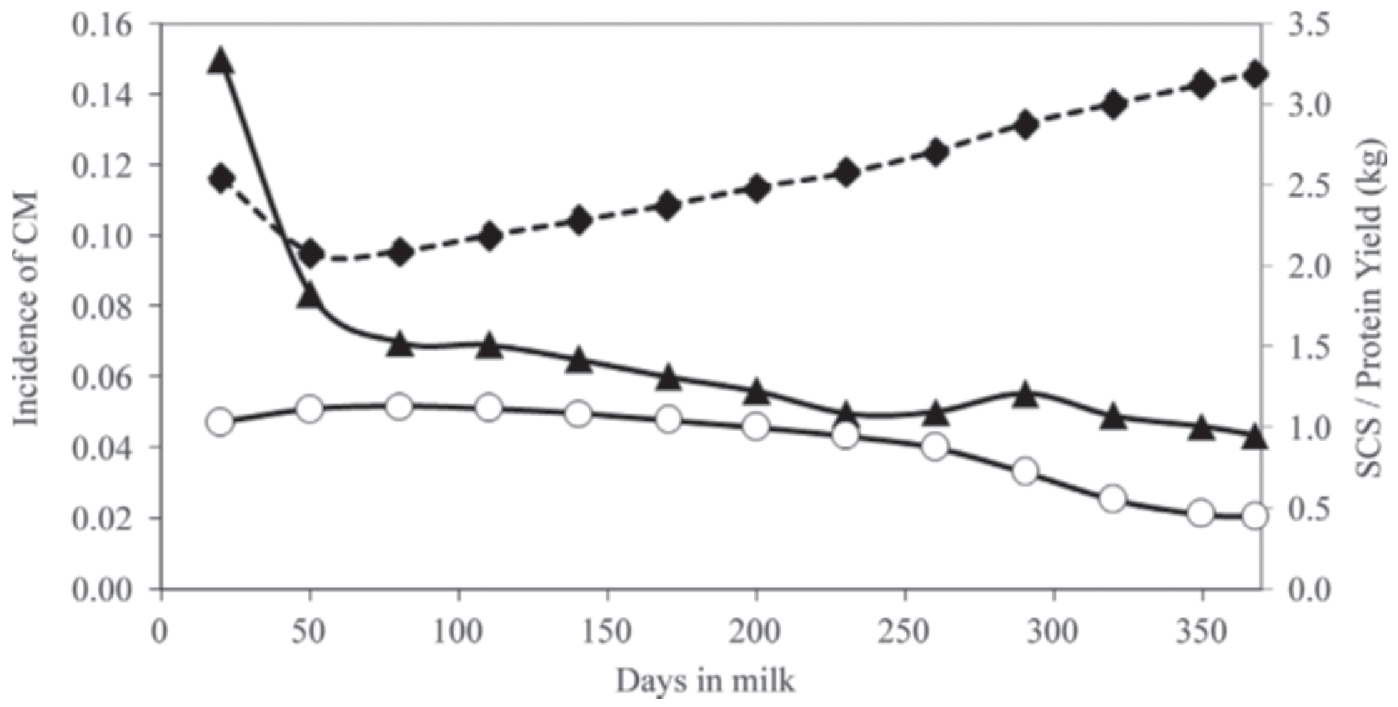

Figure 2. Incidences of clinical mastitis (CM; $\mathbf{\Delta})$ and means for test-day SCS $(\bullet)$ and test-day protein yield $(O)$ by DIM.

$\mathrm{CM}$ as found in our study might be attributed to health data recording in herds with good management. We used data from selected contract herds, which are also harmonized with regard to data recording and datarecording systems. Harmonization across herds is based on efforts of the breeding organization (e.g., by employing additional personal for contract herd support and supervision). Such advantages of contract herds for genetic parameter estimation (e.g., higher data quality and a pronounced genetic differentiation in herds with better management) were summarized by Schierenbeck et al. (2011). A further explanation for higher heritabilities for CM in our study compared with Carlén et al. (2009) is based on the chosen model, because Carlén et al. (2009) used a linear RRM. Theoretical expectations for heritabilities for CM from different models were also verified based by Vazquez et al. (2009). Following the theoretical background (Dempster and Lerner, 1950), heritabilities on the underlying heritability from threshold models are larger compared with linear model applications with estimates on the observed scale.

Genetic correlations in the same trait (CM) between different test days were close to 1 for adjacent test days, but were close to zero for test days far apart. Results are illustrated in Figure 4 for selected 20, 160, and 300 $\mathrm{d}$ after calving, and confirm previous genetic correlations from linear RRM (Carlén et al., 2009). The lowest genetic correlation, with $\mathrm{r}_{\mathrm{g}}=-0.14$, was estimated for the combination of d 20 with d 365. Negative genetic correlations suggest a reranking of sires, resulting in totally different CM top lists for the beginning and for the end of lactation. A physiological explanation might be that different genes are expressed with changes in time and aging of the cow, leading to the conclusion that $\mathrm{CM}$ at the beginning and $\mathrm{CM}$ at the end of lactation are genetically different traits (Heringstad et al., 2003). Again, the reduced data set combined with low disease incidences at the extreme late stage of lactation should be kept in mind when interpreting genetic parameter estimates. Application of RRM to binary health data allows selection of genetically best sires within lactation stages. Assume 2 sires A and B with identical lactation $\mathrm{EBV}$ for $\mathrm{CM}$, but sire $\mathrm{A}$ is superior at the beginning and sire B is superior at the end of lactation. Herd X, having severe problems with CM directly after calving, will select sire A, and farm Y, which intends to improve $\mathrm{CM}$ at the end of lactation, will select sire B. Daily EBV for test-day production data were used to derive parameters describing lactation persistency (e.g., Jamrozik et al., 1997), and similar applications might be useful based on EBV for health data.

\section{Genetic Correlations Between CM and Protein Yield, and CM and SCS in the Course of Lactation}

Daily genetic correlations between liability to CM and protein yield were low to moderate and, therefore, contrary to the reports of pronounced genetic antagonism. For identical test days, genetic correlations were $-0.03,0.11$, and 0.18 for 20, 160, and 300 DIM, respectively (Figure 5). Negussie et al. (2008) created a 2-trait definition for CM and they distinguished between CM observed from $7 \mathrm{~d}$ before to 30 d after calving (CM1), and CM observed from 31 to $300 \mathrm{~d}$ after calving (CM2). For the analyzed Finnish Ayrshire population, the genetic correlation between 


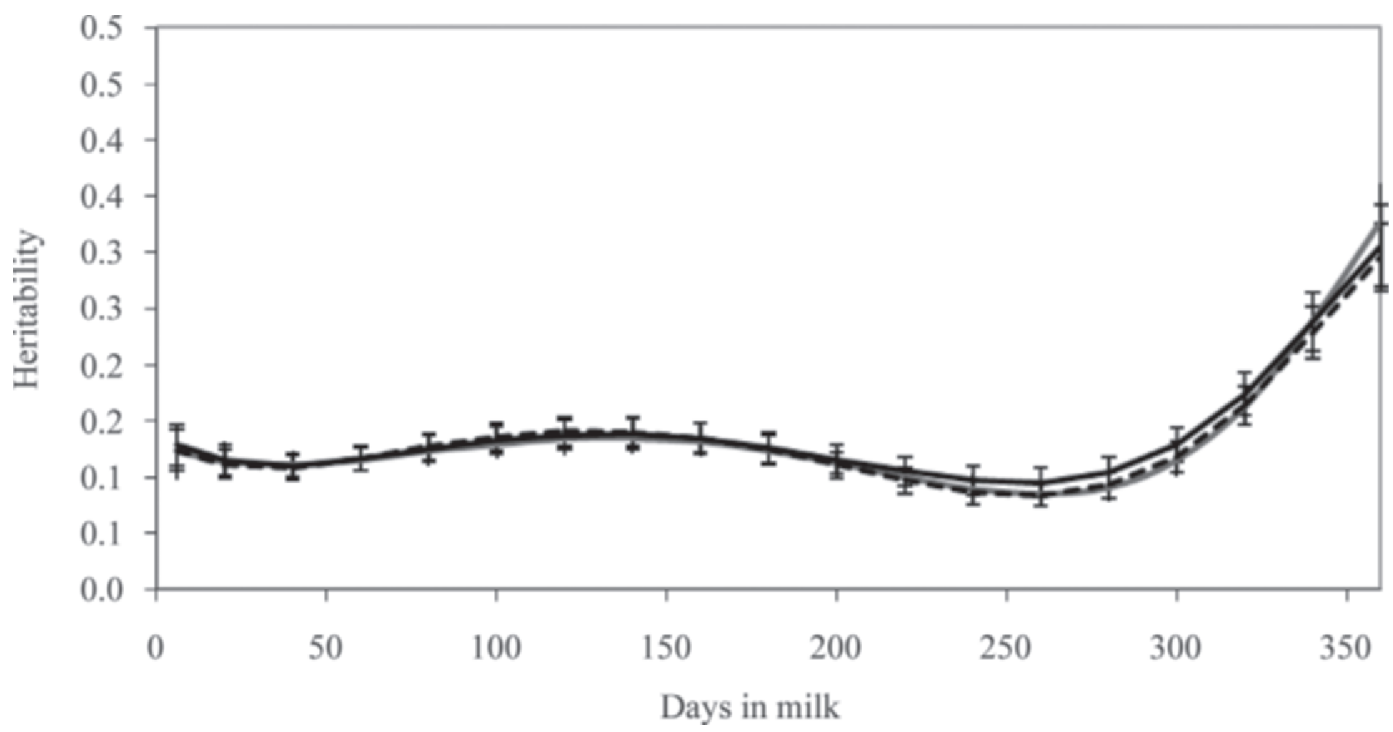

Figure 3. Posterior means for daily heritabilities for liability to clinical mastitis (CM) by DIM from the univariate threshold random regression model (gray solid line), from the bivariate threshold-linear random regression model including CM and protein yield (black solid line), and from the bivariate threshold-linear random regression model including CM and SCS (black dashed line). Error bars represent SD of posterior estimates.

CM1 and test-day milk yield at DIM 30 was 0.51 , and 0.49 between CM2 and test-day milk yield at DIM 310. Antagonistic relationships of a similar correlation level were reported by Carlén et al. (2004) in Swedish Holstein cows. Nevertheless, the literature that focused on genetic associations between $\mathrm{CM}$ and productivity reveals a heterogeneous picture, and also favorable relationships were reported, even for chromosome segments and genomic marker data (Bagheri et al., 2013). In our present study, the highest genetic correlation of value 0.32 , indicating an antagonistic relationship, was found between protein yield recorded at d 20 and

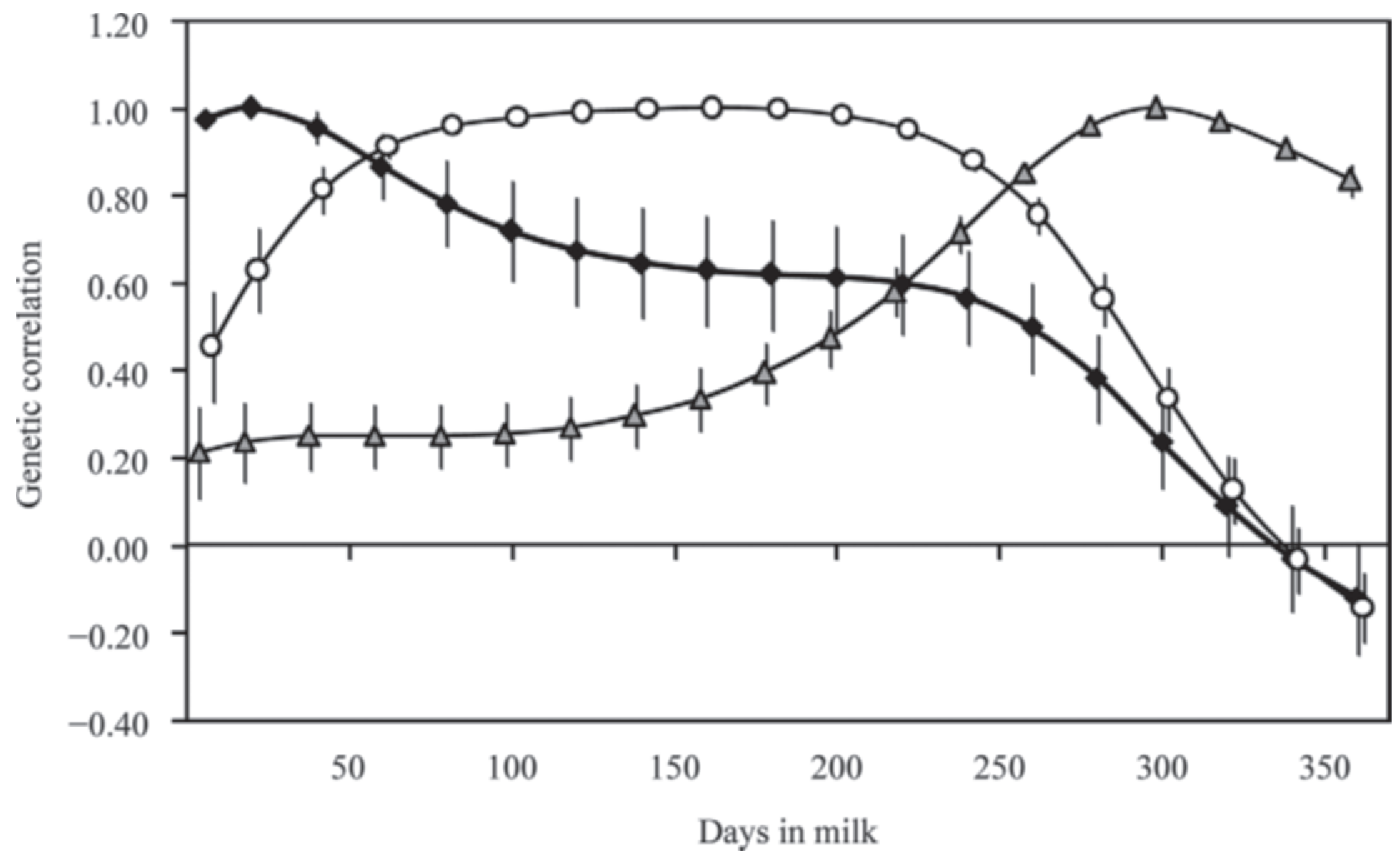

Figure 4. Posterior means for genetic correlations between daily liability to clinical mastitis at selected test days and remaining test days in the course of lactation. Black squares $=\mathrm{d} 20$; open circles $=\mathrm{d} 160$; gray triangles $=\mathrm{d}$ 300. Error bars represent SD of posterior estimates. 
CM recorded at d 120. Such time-lagged associations were also found when applying recursive models to infer relationships between protein yield and CM (Rehbein et al., 2013), between milk yield and CM (Wu et al., 2008), and between productivity and different types of claw disorders (König et al., 2008). Hence, the impact of physiological stress due to high protein yield, resulting in a negative energy balance (Collard et al., 2000) directly after calving, adversely affected udder health throughout lactation until 280 DIM. Also, reactions on environmental stress (heat stress) were time lagged. This phenomenon was observed when studying the impact of heat stress in terms of temperature $x$ humidity indices on dairy cow productivity as well as on their reproductive performance (Brügemann et al., 2013).

Genetic correlations between liability to CM and SCS at identical test days varied in a narrow range between 0.61 and 0.71 from the period directly after calving to $260 \mathrm{~d}$ after calving (Figure 6). Such a range for genetic correlations between CM and the udder health indicator SCS is in agreement with results from lactation models (e.g., Emanuelson et al., 1988) or from models that defined CM early and late in lactation as different traits (Negussie et al., 2008). Negussie et al. (2008) reported estimates lower than 0.60 when correlating CM1 with test-day SCS from the middle or the end of lactation, or when correlating CM2 with test-day SCS directly after calving. In our present study and with regard to the late stage of lactation, genetic correlations between liability to $\mathrm{CM}$ and SCS continuously decreased. The lowest value, with $\mathrm{r}_{\mathrm{g}}=0.24$, was estimated at $\mathrm{d} 365$. The low genetic correlations might be attributed to the decreasing CM incidences and increasing SCS values in the late stage of lactation (Figure 2). Consequently, with regard to the end of lactation, SCS is only a weak to moderate predictor for $\mathrm{CM}$ on the phenotypic as well as on the genetic scale, and underlines the necessity of direct recording of CM to achieve substantial improvements of the udder health status in the German Holstein population.

\section{Comparison of EBV for CM from Different Models in the Course of Lactation}

The correlation between lactation EBV for CM from the RM and from the RRM using only the 74 influential sires with more than 60 daughters was 0.97 (Table 2 ). Hence, when basing selection decisions of sires for CM on lactation EBV, the same sires will be chosen irrespective of the statistical modeling. Correlations between EBV from the MTM for different segments with lactation EBV from the RRM were in a range from 0.87 to 0.95 , and basically confirm associations found by Reents et al. (1997) when evaluating cow EBV from MTM and RRM for production traits. Also, when correlating EBV for CM form individual test days with lactation EBV for CM, the correlations were quite high. Only for test days at the very end of lactation (DIM >300) did correlations between test-day EBV and lactation EBV decrease below 0.80 , and this indicates a reranking of

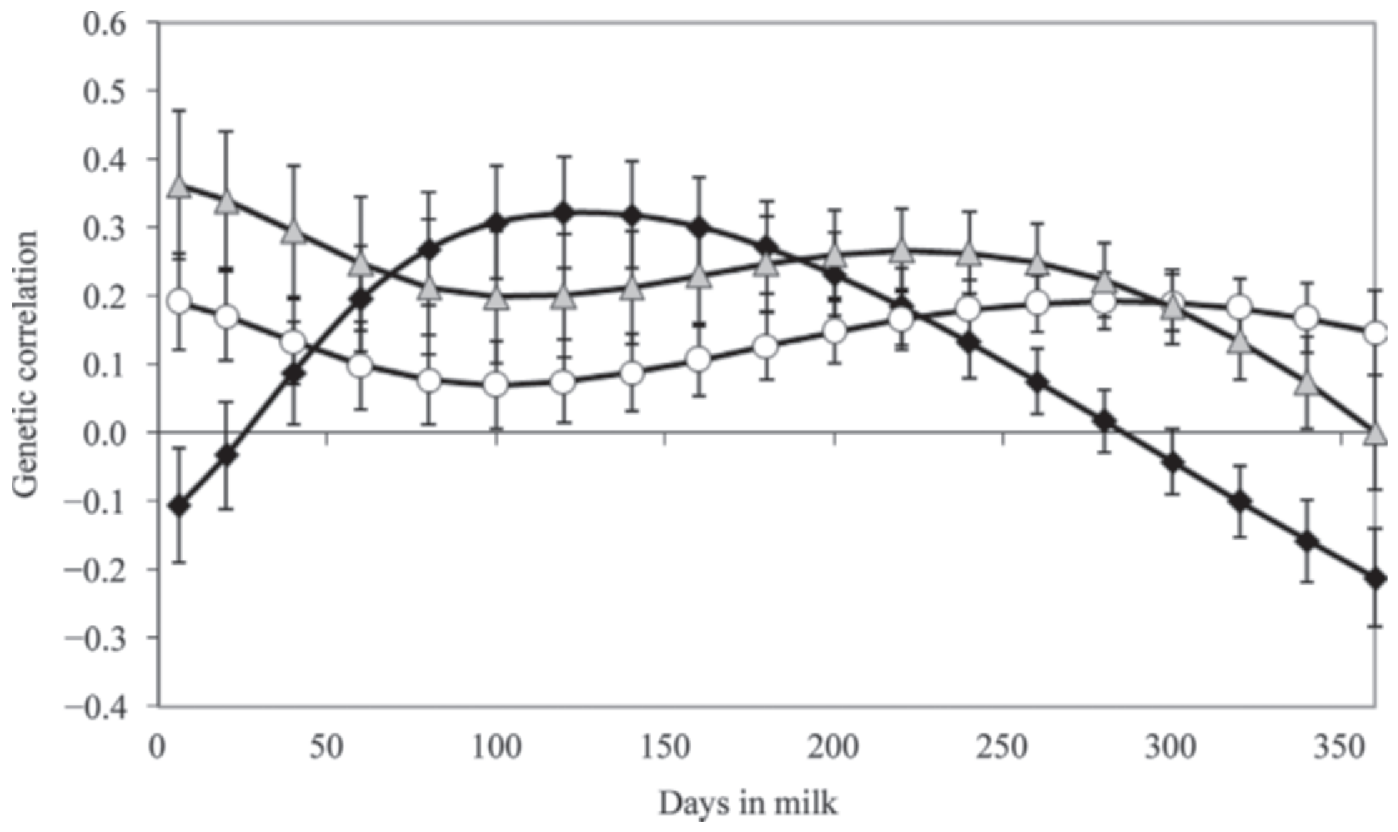

Figure 5. Posterior means for genetic correlations between daily liability to clinical mastitis and protein yield at d 20 (black diamonds), at d 160 (open circles), and at d 300 (gray triangles). Error bars represent SD of posterior estimates. 


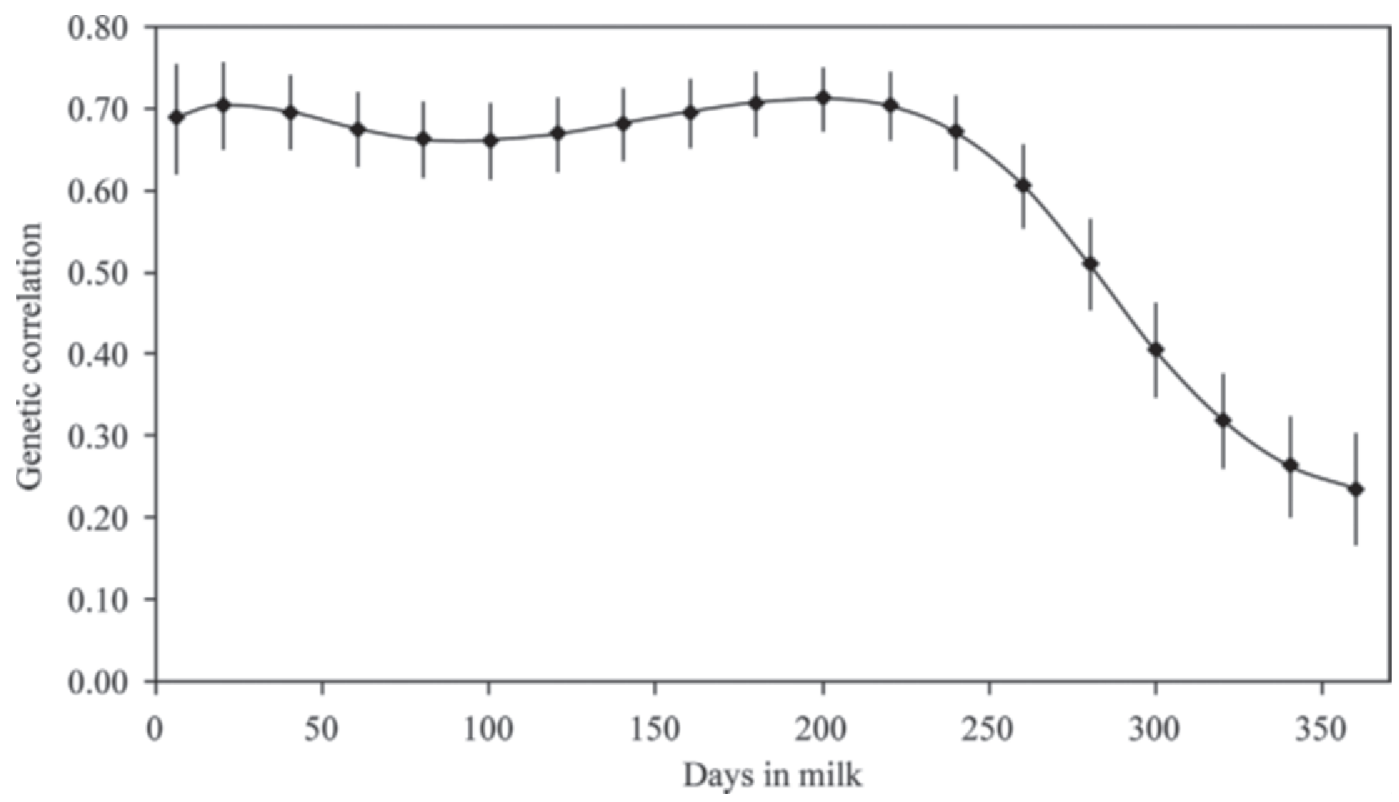

Figure 6. Posterior means for genetic correlations between daily liability to clinical mastitis and SCS at corresponding test days in the course of lactation. Error bars represent SD of posterior estimates.

sires for different lactation stages. Also, correlations between EBV for CM for different periods from the MTM and the EBV from the RM were close to unity (also for period IV). The correlation between the EBV for $\mathrm{CM}$ in period IV and the test-day EBV at $300 \mathrm{~d}$ was 0.72 . The latter 2 arguments support the argument that application of RRM allows more detailed genetic differentiation at individual test days at the very end of lactation compared with the clustering of CM cases into distinct time periods.

Correlations between test-day CM EBV followed the pattern of genetic correlations as presented in Figure
4. From the theoretical perspective and following Calo et al. (1973), correlations between EBV from elite sires can be interpreted as genetic correlations. However, due to accuracies of EBV lower than 1, correlations between EBV are always an underestimation of the genetic correlation. Correlations were moderate between the EBV for CM early in lactation and the EBV for CM extremely late in lactation. For example, the correlation was 0.27 between test $d 20$ and 50 , and 0.28 between test d 50 and 300. Additionally, we ran a genetic evaluation for CM using a univariate threshold RRM based on Legendre polynomials of order 4 . The correlation

Table 2. Correlations between sire EBV for clinical mastitis from the repeatability model (RM), from the multiple-trait model (MTM), and from the univariate random regression model (RRM) for selected test days and the sum of lactation ${ }^{1}$

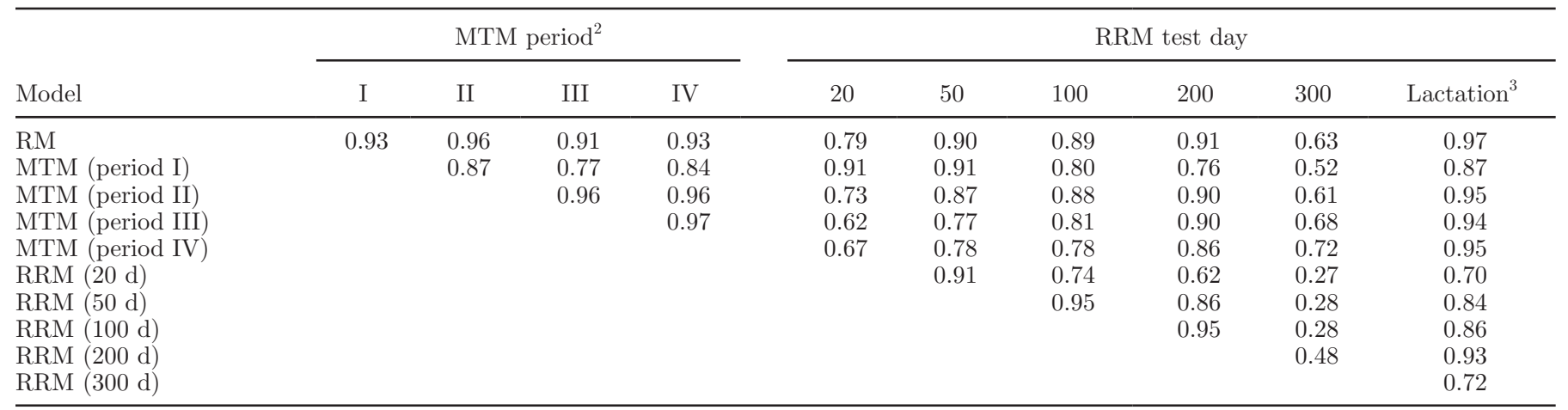

${ }^{1}$ Restriction: 74 sires with at least 60 daughters.

${ }^{2}$ Period $\mathrm{I}=$ test days from d 1 to 65 ; period II = test days from d 66 to 180 ; period III = test days from d 181 to 270 ; period IV $=$ test days from d 271 to 360 .

${ }^{3}$ Lactation $=$ sum of daily EBV from the RRM. 
Table 3. Correlations between sire EBV for clinical mastitis from different models [repeatability model (RM), multiple-trait model (MTM), and random regression model $(\mathrm{RRM})]$ and their EBV from the official national genetic evaluation ${ }^{1}$

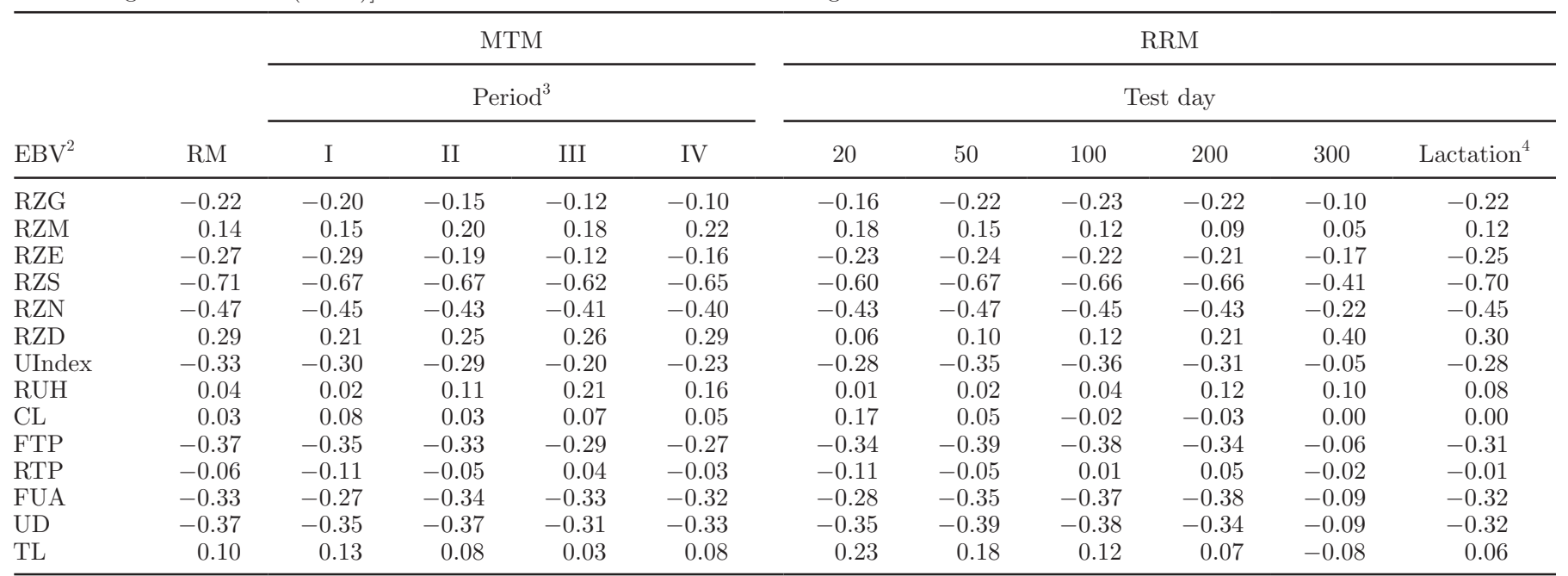

${ }^{1}$ Restriction: 74 sires with at least 60 daughters.

${ }^{2} \mathrm{RZG}=$ overall index; RZM = production index; RZE = conformation index; RZS = SCS index; RZN = longevity index; RZD = milking speed index; UIndex $=$ udder type trait index; RUH $=$ rear udder height; $\mathrm{CL}=$ central ligament; FTP $=$ front teat placement; RTP $=$ rear teat position; FUA = fore udder attachment; UD = udder depth; TL = teat length.

${ }^{3}$ Period $\mathrm{I}=$ test days from d 1 to 65 ; period II = test days from d 66 to 180 ; period III = test days from d 181 to 270 ; period IV $=$ test days from d 271 to 360 .

${ }^{4}$ Lactation $=$ sum of daily EBV from the RRM.

between lactation EBV for CM from the RRM with Legendre order 3 and the RRM with Legendre order 4 was 0.97 , and also correlations at the same test days were higher than 0.95 throughout. Hence, from a practical point of view, the choice of polynomials of either 3 or 4 for genetic evaluations of binary CM has no effect on sire rankings.

\section{Correlations Between EBV for CM and EBV from Indicator Traits in the Course of Lactation}

Correlations between EBV for CM estimated with different models and chosen EBV from the official national genetic evaluation for the 74 influential sires are presented in Table 3. The EBV for CM are standardized to a mean of 0 and a standard deviation of 1 and, consequently, a negative EBV for CM is favorable in the sense of breeding (= low incidence of infected daughters). For EBV from the national genetic evaluation with mean of 100 and a standard deviation of 12, the situation is opposite: the higher the EVB, the genetically better the bull. For the interpretation of correlations between EBV for $\mathrm{CM}$ and $\mathrm{EBV}$ for traits from the official genetic evaluation, it is important to know that negative correlations are favorable from a dairy cattle breeding perspective. In consequence, positive correlations indicate genetic antagonisms. The only exceptions are the type traits FTP, RTP, and TL with an intermediate optimum.
A slight indication of a genetic antagonism and reflecting results in Figure 5 (showing the genetic correlations between CM and protein yield) was found when correlating $\mathrm{EBV}$ for $\mathrm{CM}$ with the overall production index. Correlations ranged between -0.10 and -0.26 (Table 3). Estimated breeding values for CM were favorably correlated with longevity, conformation, and with the udder health indicator RZS. Correlations between EBV for CM and RZS were in a narrow range from -0.62 to -0.72 , which generally reflects the practical importance of SCS for the use in populationwide recording systems. However, genetic gain for $\mathrm{CM}$ will be substantially larger when focusing on directrecording systems for CM. This assumption is based on the genetic parameter estimates from the present study, because heritabilities for CM were slightly higher than heritabilities for SCS, and genetic correlations between $\mathrm{CM}$ and SCS ranged between approximately 0.60 and approximately 0.70. A maximal heritability for SCS in the course of lactation with a value of 0.13 was estimated at 360 DIM.

Practical implementation of such ideas for direct health recording, which were intensively discussed by Swalve and König (2007) and by Schierenbeck et al. (2011), might be possible in selected contract herds. A population-wide recording system for $\mathrm{CM}$ might be difficult to implement. Estimated breeding values for $\mathrm{CM}$ were positively correlated with breeding values for milking speed (RZD). The correlation of 0.30 for CM 
from the RRM lactation EBV and RZD is in agreement with the known antagonistic genetic relationship between udder health and milking speed (e.g., Boettcher et al., 1998).

Among linear type traits of the udder composite, the strongest and most favorable correlations with $\mathrm{CM}$ were found for udder depth and for fore udder attachment ( -0.32 for the lactation CM EBV from the RRM). For FTP, narrow placements are desired for improving udder health (the correlation was -0.33 for the lactation CM EBV from the RRM), but in contrast for RTP, an intermediate value is optimal. Correlations between EBV for CM and remaining type traits of the udder composite (rear udder height, central ligament, and TL) were close to zero. Based on the only moderate genetic correlations between EBV for CM and type traits, or correlations close to zero, the general importance of linear type trait scoring is questionable. Results from this present udder health study are in line with results on studies on claw disorders (e.g., Koenig et al., 2005; Gernand et al., 2013), and support recording of health traits to implement direct selection strategies on $\mathrm{CM}$ instead of indirect selection strategies based on indicator type traits. Health trait recording and the use of health traits in breeding programs causes additional costs, but refinancing of such systems is possible by the disestablishment of type trait scoring. In a final step, the direct inclusion of health traits into overall breeding goals is imperative.

\section{CONCLUSIONS}

Heritabilities for CM from threshold RRM in the course of lactation were quite constant, but substantially increased during the late stage of lactation. This increase in heritabilities for $\mathrm{CM}$ at the end of lactation is presumably due to data limitations in combination with decreasing disease incidences and, in consequence, suggests threshold RRM applications only to binary data sets characterized by high data quantity and data quality. From a methodological perspective, CM EBV from the RRM were almost identical to CM EBV from the MTM for identical time periods. Correlations between lactation EBV from the 3 different models RRM, MTM, and RM were close to 1. A substantial decline in genetic correlations for the same trait CM was observed for test days far apart, and point to the advantage of RRM to select superior sires for distinct time intervals. Higher heritabilities for liability to CM than heritabilities for the udder health indicator trait SCS, moderate genetic correlations between CM and SCS, and only weak to moderate correlations between $\mathrm{CM}$ and type traits suggest the implementation of direct-recording schemes for $\mathrm{CM}$, and the inclusion of $\mathrm{CM}$ in overall breeding goals.

\section{ACKNOWLEDGMENTS}

This study was conducted in dairy cattle farms belonging to the breeding organization Landesverband Thüringer Rinderzüchter (LTR, Erfurt, Germany). The authors thank LTR and especially U. Philipp for the technical support with regard to health data recording.

\section{REFERENCES}

Bagheri, M., R. Miraie-Ashtiani, M. Moradi-Shahrbabak, A. NejatiJavaremi, A. Pakdel, U. U. von Borstel, E. C. G. Pimentel, and S. König. 2013. Selective genotyping and logistic regression analyses to identify favorable SNP-genotypes for clinical mastitis and production traits in Holstein dairy cattle. Livest. Sci. 151:140-151.

Baldi, F., L. G. Albuquerque, and M. M. Alencar. 2010. Random regression models on Legendre polynomials to estimate genetic parameters for weights from birth to adult age in Canchim cattle. J. Anim. Breed. Genet. 127:289-299.

Boettcher, P. J., J. C. Dekkers, and B. W. Kolstad. 1998. Development of an udder health index for sire selection based on somatic cell score, udder conformation, and milking speed. J. Dairy Sci. 81:1157-1168.

Brügemann, K., E. Gernand, U. U. von Borstel, and S. König. 2011. Genetic analyses of protein yield in dairy cows applying random regression models with time-dependent and temperature $\times$ humidity-dependent covariates. J. Dairy Sci. 94:4129-4139.

Brügemann, K., E. Gernand, U. U. von Borstel, and S. König. 2013. Application of random regression models to infer the genetic background and phenotypic trajectory of binary conception rate by alterations of temperature $\times$ humidity indices. Livest. Sci. 157:389-396.

Calo, L. L., R. E. McDowell, L. D. VanVleck, and P. D. Miller. 1973. Genetic aspects of beef production among Holstein-Friesians pedigree selected for milk production. J. Anim. Sci. 37:676-682.

Carlén, E., K. Grandinson, U. Emanuelson, and E. Strandberg. 2009. Random regression models for genetic evaluation of clinical mastitis in dairy cattle. Animal 3:1100-1108.

Carlén, E., E. Strandberg, and A. Roth. 2004. Genetic parameters for clinical mastitis, somatic cell score, and production in the first three lactations of Swedish Holstein cows. J. Dairy Sci. 87:30623070.

Collard, B. L., P. J. Boettcher, J. C. M. Dekkers, D. Petitclerc, and L. R. Schaeffer. 2000. Relationships between energy balance and health traits of dairy cattle in early lactation. J. Dairy Sci. $83: 2683-2690$

de Haas, Y., H. W. Barkema, and R. V. Veerkamp. 2002. Genetic parameters of pathogen-specific incidence of clinical mastitis in dairy cows. Anim. Sci. 74:233-242.

Dempster, E. R., and I. M. Lerner. 1950. Heritability of threshold characters. Genetics 35:212-236.

Emanuelson, U., B. Danell, and J. Philipsson. 1988. Genetic parameters for clinical mastitis, somatic cell counts, and milk production estimated by multiple-trait restricted maximum likelihood. J. Dairy Sci. 71:467-476.

Feucker, W., and R. Staufenbiel. 2003. Zentraler Diagnoseschlüssel Rind. Accessed Mar. 16, 2010. http://www.portal-rind.de/index. php? module $=$ Downloads $\&$ func $=$ prep_hand_out $\&$ lid $=17$.

Gernand, E., D. A. Döhne, and S. König. 2013. Genetic background of claw disorders in the course of lactation and their relationships with type traits. J. Anim. Breed. Genet. 130:435-444.

Gernand, E., P. Rehbein, U. U. von Borstel, and S. König. 2012. Incidences of and genetic parameters for mastitis, claw disorders and 
common health traits recorded in dairy cattle contract herds. J. Dairy Sci. 95:2144-2156.

Heringstad, B., Y. M. Chang, D. Gianola, and G. Klemetsdal. 2003. Genetic analyses of longitudinal trajectory of clinical mastitis in first-lactation Norwegian cattle. J. Dairy Sci. 86:2676-2683.

Hertl, J. A., Y. H. Schukken, D. Bar, G. J. Bennett, R. N. González, B. J. Rauch, F. L. Welcome, L. W. Tauer, and Y. T. Gröhn. 2011. The effect of recurrent episodes of clinical mastitis caused by gram-positive and gram-negative bacteria and other organisms on mortality and culling in Holstein dairy cows. J. Dairy Sci. 94:4863-4877.

Holtenius, K., K. Persson Waller, B. Essén-Gustavsson, P. Holtenius, and C. Hallén Sandgren. 2004. Metabolic parameters and blood leukocyte profiles in cows from herds with high or low mastitis incidence. Vet. J. 168:65-73.

Jamrozik, J., L. R. Schaeffer, and J. C. M. Dekkers. 1997. Genetic evaluation of dairy cattle using test day yields and random regression model. J. Dairy Sci. 80:1217-1226.

Koenig, S., A. R. Sharifi, H. Wentrot, D. Landmann, M. Eise, and H. Simianer. 2005. Genetic parameters of claw and foot disorders estimated with logistic models. J. Dairy Sci. 88:3316-3325.

König, S., K. Brügemann, and E. C. G. Pimentel. 2013. Breeding strategies for animal welfare and climate protection: What is possible and what is necessary? Züchtungskunde 85:22-33.

König, S., X.-L. Wu, D. Gianola, B. Heringstad, and H. Simianer. 2008. Exploration of relationships between claw disorders and milk yield in Holstein cows via recursive linear and threshold models. J. Dairy Sci. 91:395-406.

Madsen, P., and J. Jensen. 2000. A user's guide to DMU. A package for analysing multivariate mixed models. Version 6 , release 4 . Danish Institute of Agricultural Sciences, Research Centre Foulum, Tjele, Denmark.

Meyer, K., H.-U. Graser, and K. Hammond. 1989. Estimates of genetic parameters for first lactation test day production of Australian black and white cows. Livest. Prod. Sci. 21:177-199.

Negussie, E., I. Strandén, and E. A. Mäntysaari. 2008. Genetic associations of clinical mastitis with test-day somatic cell score and milk yield during first lactation of Finnish Ayrshire cows. J. Dairy Sci. 91:1189-1197.

Ptak, E., and L. R. Schaeffer. 1993. Use of test day yields for genetic evaluation of dairy sires and cows. Livest. Prod. Sci. 34:23-34.
Reents, R., L. Dopp, and F. Reinhardt. 1997. Experiences with a genetic evaluation using test day data. Interbull Bull. 16:48-52.

Reents, R., J. Jamrozik, L. R. Schaeffer, and J. C. M. Dekkers. 1995. Estimation of genetic parameters for test day records of somatic cell score. J. Dairy Sci. 78:2847-2857.

Rehbein, P., K. Brügemann, T. Yin, U. König v. Borstel, X.-L. Wu, and S. König. 2013. Inferring relationships between clinical mastitis, productivity and fertility: A recursive model application including genetics, farm associated herd management, and cowspecific antibiotic treatments. Prev. Vet. Med. 112:58-67.

Rupp, R., and D. Boichard. 1999. Genetic parameters for clinical mastitis, somatic cell score, production, udder type traits, and milking ease in first lactation Holsteins. J. Dairy Sci. 82:2198-2204.

Sadeghi-Sefidmazgi, A., M. Moradi-Shahrbabak, A. Nejati-Javaremi, S. R. Miraei-Ashtiani, and P. R. Amer. 2011. Estimation of economic values and financial losses associated with clinical mastitis and somatic cell score in Holstein dairy cattle. Animal 5:33-42.

Schierenbeck, S., F. Reinhardt, R. Reents, H. Simianer, and S. König. 2011. Identification of informative cooperator herds for progeny testing based on yield deviations. J. Dairy Sci. 94:2071-2082.

Swalve, H. H. 2000. Theoretical basis and computational methods for different test-day genetic evaluation methods. J. Dairy Sci. $83: 1115-1124$.

Swalve, H. H., and S. König. 2007. Test herds in dairy cattle breeding programmes 1st communication: General considerations. Züchtungskunde 79:249-262.

Tsuruta, S., I. Misztal, C. Huang, and T. J. Lawlor. 2009. Bivariate analysis of conception rates and test-day milk yields in Holsteins using a threshold-linear model with random regressions. J. Dairy Sci. 92:2922-2930.

Vazquez, A. I., D. Gianola, D. Bates, K. A. Weigel, and B. Heringstad. 2009. Assessment of Poisson, logit, and linear models for genetic analysis of clinical mastitis in Norwegian Red cows. J. Dairy Sci. 92:739-748.

Wu, X.-L., B. Heringstad, and D. Gianola. 2008. Exploration of lagged relationships between mastitis and milk yield in dairy cows using a Bayesian structural equation Gaussian-threshold model. Genet. Sel. Evol. 40:333-357.

Zoche-Golob, V., and S. Spilke. 2013. Herd-specific estimation of milk vield reduction due to recurrent clinical mastitis. Berl. Munch. Tierärztl. Wochenschr. 126:269-276. 